\title{
RISK FACTORS FOR CARDIOVASCULAR EVENTS IN RURAL NIGERIA: A CROSS SECTIONAL SURVEY AND A REVIEW OF THE CURRENT LITERATURE
}

\author{
Anthonia A. Ikpeme ${ }^{\star \dagger, 1}$, Nchiewe E. Ani², Edoise M. Isiwele ${ }^{3}$, Andrew E. \\ Ekpenyong $^{4}$, Emmanuel E. Ekanem ${ }^{5}$ \\ ${ }^{1}$ Department of Radiology, University of Calabar, Nigeria \\ ${ }^{2}$ Department of Radiology, University of Calabar, Nigeria \\ ${ }^{3}$ Department of Urology, University of Calabar, Nigeria \\ ${ }^{4}$ Department of Physics, University of Creighton, Nebraska. USA \\ ${ }^{5}$ Department of Paediatrics, University of Calabar, Nigeria \\ DOI https://doi.org/10.15520/ijmhs.v9i4.2533
}

Accepted 1 Apl 2019; Received 1 Mar 2019; Publish Online 25 Apl 2019

Reviewed By: Dr
Daniel V.
Department: Medical

\begin{abstract}
Introduction: Over $80 \%$ of cardiovascular deaths take place in low and middle income countries. These cardiovascular deaths are caused by modifiable risk factors. Evidence is emerging that some of these factors maybe even more prevalent in rural areas which are generally underserved.

Aim: The aim of this study was to record risk factors for cardiovascular disease in rural communities in south southern Nigeria and review some related literature.

Methods: A cross sectional study during clinical outreach activities that took place in 2016 to 2018 in several rural and few urban communities in Cross River State, Nigeria. Participating individuals gave full consent and ethical clearance obtained. Socio-demographic data, Anthropometric data and Blood sugar measurements were obtained. Data extracted was transferred into EXCEL thereafter analysis was done using SPSS version 21. p values less than 0.05 were deemed statistically significant. Tests of significance included Anova, chi square and student t- tests.

Results: Total population investigated over the 3 year period was 504. (2016-33.1\%), (2017-37.9\%), (2018-28\%) with a Female: Male distribution of 1:1.

Most participants tended to be overweight across the years $59.7 \%, 59.1 \%, 73.7 \%$, 2016, 2017, and 2018 respectively. The prevalence of Hypertension was $10.71 \%$. No significant gender difference in the prevalence of Hypertension (6.94\% males to $3.77 \%$ females, $\mathrm{p}=0.097)$. The prevalence of Diabetes Mellitus was $10.67 \%$. There was no significant gender prevalence $(6.67 \%$ males to $4.00 \%$ females, $\mathrm{p}=0.431)$

Conclusion: Cardiovascular disease remains relatively uncommon in Sub-Saharan Africa, despite an increasing prevalence of risk factors, but it's incidence is rising. Steps should be taken in Sub-Saharan Africa to prevent an epidemic. This involves detailed and regular screening for cardiovascular risk factors in rural communities.
\end{abstract}

Key words: RISK FACTORS, Cardio vascular disease, South South Nigeria.

\footnotetext{
^ Corresponding author.

† Email: ikpemeanthonia@yahoo.com.
}

\section{INTRODUCTION}

Cardiovascular disease is the number one cause of death worldwide. [1] Over $80 \%$ of cardiovascular deaths take place in low and middle income countries [2] and are due to modifiable risk factors. [2] High rates of hypertension and other cardiovascular risk factors and disease are being re- 


\section{RISK FACTORS FOR CARDIOVASCULAR EVENTS IN RURAL NIGERIA:A CROSS SECTIONAL SURVEY AND A REVIEW OF THE CURRENT LITERATURE

ported from different populations including low resource settings. [3] The cost of care when cardiovascular disease finally evolves will be too expensive to bear for most if not all African countries. [4] In the USA a sizable proportion of the budget is for treatment and diagnosis of cardiovascular disease : [4]

A major preventive strategy for cardiovascular disease worldwide is to aggressively identify and treat cardiovascular risk factors. [4] High blood pressure, diabetes mellitus, obesity, high cholesterol levels, alcohol consumption, lack of exercise and urbanization are some of the risk factors associated with cardiovascular deaths. [5, 6] In sub-Saharan Africa, these risk factors can be assessed easily with questionnaires/proformas, and simple laboratory tests as well as anthropometric measurements like the weight, height and Blood pressure measurements. [7]

Risk factors for cardiovascular disease (CV) in urban Africa have been extensively studied. [3, 8, 9] However evidence is emerging that some of these factors maybe even more prevalent in rural areas, [10-13] which are generally underserved. [14-17]. The aim of this study was to record risk factors for CV Disease in a rural community in southern Nigeria and review some related literature.

\section{METHOD}

This was a cross sectional study during clinical outreach activities that took place in 2016, 2017 and 2018 in several rural and urban communities in Cross River State of Nigeria. Cross River state is a state in south, south Nigeria, bordering Cameroun to the east. Its capital is Calabar, it has a population of 3.738 million in the last census. It has a total area of $20,156 \mathrm{~km}$. It has only one tertiary hospital in the city of Calabar, a General Hospital in each local government and several smaller Health centres and posts. A few up to standard private hospitals throughout the State serve in each local government.

These outreaches were sponsored by Joseph Ukpo Hospital and Research Institute (JUHRI) (a private sector organization) with the aim of setting up mobile clinics and hospitals with emphasis on the rural/urban settings who do not have access to medical care. Items donated by JUHRI included two ambulance vehicles, drugs, clinical thermometers, blood pressure equipments, glucometers, urinalysis kits and haemoglobinometers. Rural Communities visited in Cross River included four communities within Akpabuyo and Akamkpa LGAs. Urban Communities visited were St. Patrick's Parish, Ikot Ansa, a correctional facility within the city of Calabar and St. Mary's Pro Cathedral Efut Abua, also within the city of Calabar.

Ethical clearance was obtained from the Cross River State Ministry of Health Ethical Committee. Consent was also obtained from all the participants before commencement of the study. Consented participants had their sociodemographic data taken, including age, and gender. Anthropometric data recorded included weight and height. These were measured using a standard weighing scale and seca stadiometer respectively. Then they had their body mass index (BMI) calculated. [18] The blood pressure was taken using Aneroid sphygmomanometer on the right arm after 10 minutes rest in a sitting position. The first and fifth phases of Korotkoff sounds were taken as systolic and diastolic Blood pressure, respectively. [19] Average of two readings were received as the subject's blood pressure. Blood pressure measurements were done by the same volunteer nurses and doctors in all the communities. Measurements were done between the hours of 9am and 11am.

Fasting blood sugar (FBS) was determined by simple glucometer using Fine test glucometer device. Diabetes Mellitus (DM) was defined as fasting plasma glucose of at least $7.0 \mathrm{mmol} / \mathrm{L}$. [20] These were taken in the morning before 10 am after they were confirmed not to have eaten that day. Obesity was defined as BMI of at least $30 \mathrm{~kg} / \mathrm{m}^{2}$ in a patient without peripheral oedema. [21, 22]

Due to programmatic constraints, data were not available for all the parameters measured, analysis was therefore performed on a different subset of the study population for each of the risk factors.

Data was extracted from patient's proforma and transferred into EXCEL and there after SPSS version 21. Armonk,NY: (IBM Corp, 2013.) was used for analysis. Graphs were drawn using Microsoft Excel. The tests of significance included tests of variance, student's t tests, chi square and Anova. The three years period of 2016-2018 was done for the purpose of assessment of time trends. Three multivariable regression models were used to identify socio demographic and clinical factors independently associated with each of the considered CVD risk factors (Hypertension, DM, and obesity). The independent variables included in the models were important demographic factors like age, sex and clinical factors like BMI. p values less than 0.05 were deemed statistically significant.

\section{RESULTS}

Total population investigated over the 3 year period was 504. (2016-33.1\%), (2017 - 37.9\%), (2018- 29\%) with a female: male distribution of 1:1 (Table 1$)$.

The mean age of the study sample was 43.95 ( $\mathrm{SD}=$ 17.52). The most represented age group was 40-49years (Table 1 ).

The distribution of normotensive/hypertensive participants $(41.1 \%, 47.2 \%, 48.3 \%$ in 2016,2017 , and 2018 respectively.) Shown in (Table 1). The overall prevalence of 
Hypertension was $10.71 \%$ (Table 3 ). The highest blood pressure was recorded in the 70-79 age group. (Figure 2) There was no significant gender difference in hypertension. $(6.94 \%$ male to $3.77 \%$ female, $\mathrm{p}=0.097)$. (Table 2 and Figure 1 )

Most participants tended to be overweight across the years, 59.7\%, 59.1\%, 73.7\%. 2016, 2017 and 2018 respectively. (Table 1) The women were more obese than the men $(58.70 \%$ to $41.30 \%)$. (Table 4$)$

There was no significant gender difference in DM prevalence $(6.67 \%$ male to $4.00 \%$ female $)(p=0.431)$ (Table 5$)$.

\section{DISCUSSION}

About $40 \%$ of Africans with hypertension are undiagnosed, less than $30 \%$ of those who are diagnosed are on treatment and less that $20 \%$ of those on treatment have optimal blood pressure control. $[23,24]$ The current study found a prevalent rate of $10.71 \%$ in the rural population.

In a study done in Akwa Ibom, South South Nigeria, Akpan et al. [10] found a higher prevalence of hypertension in the rural communities than in the urban communities $44.3 \%$ versus $27.5 \%$.

Other studies have shown a similar trend of high prevalence of hypertension in the rural communities: $20.8 \%$ by Oladapo et al, [11] $23.6 \%$ by Andy et al [12] and as high as $46.4 \%$ by Ahaneku et al. [13] This may be attributed to the increasing age of the rural communities as most young people prefer to migrate to the cities for white collar jobs while retirees moved in opposite direction. However, in the present study hypertension was also significantly affecting the younger age group. The age group that showed the highest blood pressure was $70-79$ years. Hypertension was recorded in ages as low as 20-29. The males were affected slightly more than the women, a trend that is noted in many other studies reviewed. [10-13]

In a study by Andy et al [12] the prevalence of hypertension among Ibibio/Annang was $25.6 \%$ and $25.6 \%$ among the Efiks. This is similar to the findings in the current study among neigbouring ethnic groups.

In a study by Atinyi et al [25] in Keta, Ghana showed that adults with moderate and high risk Waist to height ratio (WHR) were 2.58 and 2.61 times more likely to have Hypertension. This trend turned out not to be statisically significant in the index study. Andy et al [12] showed that females tend to be more obese when compared with men. This trend was same in the index study.

The estimated prevalence of diabetes in Africa is $1 \%$ in rural areas, and ranges from $5 \%$ to $7 \%$ in Urban SubSaharan Africa. [26]

Studies concluded four (4) decades ago showed generally low prevalence rates of Diabetes in Nigeria $(<1 \%)$. [27]

The current prevalence of DM in Nigeria is not known though estimates show that it may likely be in the region of $8 \%-10 \%$. $[28,29]$ the index study estimated the prevalence of DM to be $10 \%$ with no significant gender difference.
Physical inactivity was not assessed in our study. This was because obtaining this information from the participants was difficult and responses given by a few proved inaccurate.

Globally there are scanty data in the prevalence of physical inactivity in Sub-Saharan Africa. However in a WHO report of national surveys in both urban and rural settings in five African countries in 2003, involving a total of 14725 individuals aged 18 to 69 years revealed a mean prevalence of physical inactivity in $19.6 \%$ of men and $22.9 \%$ of women. [14]

Although cardiovascular disease in Sub-Saharan Africa remains relatively uncommon, its risk factors is been shown in the review of literature and in the index study to be rising especially hypertension, Diabetes mellitus, overweight and obesity, physical inactivity, increased tobacco use and Dyslipidaema. The best window of opportunity for prevention of the emerging epidemic of cardiovascular heart disease in S.S.A is now $[14,30]$ such as done in the index study.

These outreaches to rural parts of the population affords communities the opportunity of specialists visits since there is generally a lack of specialists in remote or rural areas where front-line health centres are very often staffed only by nurses. ${ }^{[14]}$

During outreaches such as ours, specialists are consulted in a more rapid and interactive way and their advice increases the capacity of front-line health workers. This leads to quick referrals and better outcomes. [14]

\section{Strength and Limitations}

The current study was routinely collected as a day medical outreach in various rural and few urban communities and therefore had some limitations. Some key CVD risk factors of interest such as tobacco smoking, dyslipidaema were missing in the database, and therefore limited our capacity to explore all major CVD risk factors singly and in combination.

\section{CONCLUSION:}

Cardiovascular disease remains relatively uncommon in SSA, despite an increasing prevalence of risk factors, but its incidence is rising. The best window of opportunity for prevention of the emerging epidemic of cardiovascular heart disease in Sub-Saharan Africa is now and this involves detailed and regular screening for cardiovascular risk factors in rural and urban communities.

FUNDING: Sole sponsorship of the clinical outreach activities was By Joseph Ukpo Hospital and Research Institute, a faith based non-governmental and nonprofit making group with the aim of providing healthcare to the needy.

DATA AVAILABILITY STATEMENT: The data used to support the findings of this study are available from the corresponding author upon request.

ACKNOWELEDGEMENT: I wish to acknowledge

Prof Emmanuel Ekanem for read-ing and correcting the manuscript. 


\section{RISK FACTORS FOR CARDIOVASCULAR EVENTS IN RURAL NIGERIA:A CROSS SECTIONAL SURVEY AND A REVIEW OF THE CURRENT LITERATURE 373}

Table 1. Social Demographic and Clinical Characteristics of the Participants

\begin{tabular}{|c|c|c|c|c|c|}
\hline $\begin{array}{l}\text { CHARAC- } \\
\text { TERISTIC }\end{array}$ & 2016 & 2017 & 2018 & $\begin{array}{l}\text { OVER- } \\
\text { ALL }\end{array}$ & $\begin{array}{l}\text { p- } \\
\text { VALU }\end{array}$ \\
\hline GENDER & $(\%)$ & $(\%)$ & $(\%)$ & $(\%)$ & 0.007 \\
\hline - § & 85 & 102 & 54 & 241 & \\
\hline - $\S$ & & (53.4) & & (100) & \\
\hline \multirow[t]{3}{*}{ - $\S$} & $\begin{array}{l}82 \\
(49.1)\end{array}$ & $\begin{array}{l}89 \\
(546.7)\end{array}$ & $\begin{array}{l}92 \\
(63.0)\end{array}$ & $\begin{array}{l}263 \\
(100)\end{array}$ & \\
\hline & 167 & & 146 & 504 & \\
\hline & $(33.1)$ & $\begin{array}{l}191 \\
(37.9)\end{array}$ & (29) & (100) & \\
\hline AGE & 9 & 11 & 1 & 21 & 0.001 \\
\hline (YEARS) & 11 & 8 & 3 & 22 & \\
\hline $0-9$ & 26 & 21 & 4 & 51 & \\
\hline $10-19$ & 25 & 40 & 27 & 92 & \\
\hline $20-29$ & 36 & 33 & 48 & 117 & \\
\hline $30-39$ & 25 & 32 & 33 & 90 & \\
\hline $40-49$ & 22 & 26 & 16 & 64 & \\
\hline $50-59$ & 9 & 16 & 8 & 33 & \\
\hline $60-69$ & 4 & 4 & 6 & 14 & \\
\hline \multicolumn{6}{|l|}{ 70-79 } \\
\hline \multicolumn{6}{|l|}{$\geq 80$} \\
\hline$\overline{\mathrm{B}} \mathrm{MI}$ & $(\%)$ & $(\%)$ & $(\%)$ & (\%) & 0.001 \\
\hline (Kg/M2) & $0(0.0)$ & $2(1.1)$ & $0(0.0)$ & $2(100)$ & \\
\hline 1. § & & 43 & & & \\
\hline 2. § & $(33.8)$ & (25.1) & 23 & 113 & \\
\hline 3. § & 83 & 101 & $(17.3)$ & (100) & \\
\hline \multirow[t]{3}{*}{ 4. § } & $(59.7)$ & (59.1) & $98(73.7)$ & 282 & \\
\hline & $9(6.5)$ & 25 & & (100) & \\
\hline & & (14.6) & 12 & 46 & \\
\hline BLOOD & $(\%)$ & $(\%)$ & (\%) & (\%) & 0.049 \\
\hline \multirow[t]{2}{*}{ PRESSURE } & $0(0.0)$ & $0(0.0)$ & $0(0.0)$ & $0(0.0)$ & \\
\hline & 37 & 75 & 56 & 168 & \\
\hline $\begin{array}{l}1 . \S \\
2 . \S\end{array}$ & $\begin{array}{l}(41.1) \\
35\end{array}$ & & $\begin{array}{l}50 \\
(48.3)\end{array}$ & $\begin{array}{l}(100) \\
143\end{array}$ & \\
\hline 3. § & $(38.9)$ & $(37.1)$ & & $(100)$ & \\
\hline 4. § & 18 & 25 & $(42.2)$ & 54 & \\
\hline & $(20.0)$ & $(21.6)$ & $\begin{array}{l}11 \\
(9.5)\end{array}$ & (100) & \\
\hline
\end{tabular}

Table 2. BLOOD PRESSURE VERSUS GENDER

\begin{tabular}{lllll}
\hline BLOOD PRESSURE (\%) & MALE & $\begin{array}{l}\text { FE- } \\
\text { MALE }\end{array}$ & $\begin{array}{l}\text { TO- } \\
\text { TAL }\end{array}$ & P-VALUE \\
\hline$<90 / 60$ (Low BP) & 0 & 0 & 0 & 0.097 \\
& $(0.0)$ & $(0.0)$ & & \\
$>90 / 60$ but $<120 / 80$ & 96 & 72 & 168 & \\
(Ideal and Healthy BP) & $(53.3)$ & $(38.9)$ & $(100)$ & \\
$>120 / 80$ but $<140 / 90$ & 65 & 78 & 143 & \\
(Normal/Pre-high BP) & $(36.1)$ & $(42.2)$ & $(100)$ & \\
$>140 / 90$ (High BP) & 35 & 19 & 54 & \\
& $(19.4)$ & $(10.3)$ & $(100)$ & \\
TOTAL & $180(100) 185(100) 365$ \\
& \multicolumn{5}{c}{$(100)$} \\
\hline
\end{tabular}

Prevalence of hypertension was $10.71 \%$ (95\% CI $6.94 \%$ to 3.77 ). There was no significant gender difference gender prevalence ( $6.94 \%$ male to $3.77 \%$ female, $\mathrm{p}=0.097$ )
Table 3. Prevalence of hypertension and Obesity among participants over a three year period

\begin{tabular}{lcccl}
\hline DIAGNOSIS & 2016 & 2017 & 2018 & $\begin{array}{l}\text { Over all } \\
\text { Prevalence (\%) }\end{array}$ \\
$\begin{array}{l}\text { HYPERTEN- } \\
\begin{array}{l}\text { SION } \\
(\%)\end{array}\end{array}$ & 10.78 & 13.09 & 7.53 & 10.71 \\
OBESITY (\%) & 5.39 & 13.09 & 7.53 & 9.12 \\
\hline
\end{tabular}

Table 4. BMI VERSUS GENDER

\begin{tabular}{|c|c|c|c|c|c|}
\hline BMI $(\mathrm{Kg} / \mathrm{m} 2)$ & $\begin{array}{l}\text { MALE } \\
(\%)\end{array}$ & $\begin{array}{l}\text { FE- } \\
\text { MALE } \\
(\%)\end{array}$ & $\begin{array}{l}\text { TO- } \\
\text { TAL } \\
(\%)\end{array}$ & \multicolumn{2}{|c|}{$\begin{array}{l}\text { STATIS- } \\
\text { TICS }\end{array}$} \\
\hline $\begin{array}{l}\text { Underweight } \\
(\leq 18.49)\end{array}$ & $\begin{array}{l}0 \\
(0.00)\end{array}$ & $2(100)$ & $\begin{array}{l}2 \\
(0.45)\end{array}$ & \multicolumn{2}{|c|}{$\begin{array}{l}\mathrm{t}(443), \text { df } 340= \\
0.564\end{array}$} \\
\hline $\begin{array}{l}\text { Normal weight } \\
(18.5-24.49)\end{array}$ & $\begin{array}{l}44 \\
(38.94)\end{array}$ & $\begin{array}{l}69 \\
(61.06)\end{array}$ & $\begin{array}{l}113 \\
(25.45)\end{array}$ & $\mathrm{P}=$ & 0.573 \\
\hline $\begin{array}{l}\text { Overweight } \\
(25-29.90)\end{array}$ & $\begin{array}{l}136 \\
(48.23)\end{array}$ & $\begin{array}{l}146 \\
(51.77)\end{array}$ & $\begin{array}{l}282 \\
(63.51)\end{array}$ & & \\
\hline Obesity $(\geq 30)$ & $\begin{array}{l}19 \\
(41.30)\end{array}$ & $\begin{array}{l}27 \\
(58.70)\end{array}$ & $\begin{array}{l}46 \\
(10.36)\end{array}$ & & \\
\hline
\end{tabular}

Table 5. BLOOD SUGAR VERSUS GENDER

\begin{tabular}{lllll}
\hline $\begin{array}{l}\text { Fasting Blood Sugar } \\
\text { mmol/L }(\mathrm{n}=\%)\end{array}$ & Male & $\begin{array}{l}\text { Fe- } \\
\text { male }\end{array}$ & Total & P- Value \\
\hline Low $(<3.9)$ & 0 & 0 & 0 & 0.431 \\
Normal (4-5.6) & $(0.0)$ & $(0.0)$ & $(0.0)$ & \\
& 38 & 11 & 49 & \\
Impaired Glucose & $(82.6)$ & $(37.9)$ & $(65.3)$ & \\
(5.6-6.9) & 3 & 15 & 18 & \\
Diabetic & $(6.5)$ & $(51.7)$ & $(24)$ & \\
& 5 & 3 & 8 & \\
Total & $(10.9)$ & $(10.3)$ & $(10.7)$ & \\
& 46 & 29 & 75 & \\
\hline
\end{tabular}

Prevalence of Diabetes was $10.67 \%$ (95\% CI $6.67 \%$ to 4.00 ). There was no significant gender difference gender prevalence ( $6.67 \%$ male to $4.00 \%$ female, $\mathrm{p}=0.431$ )

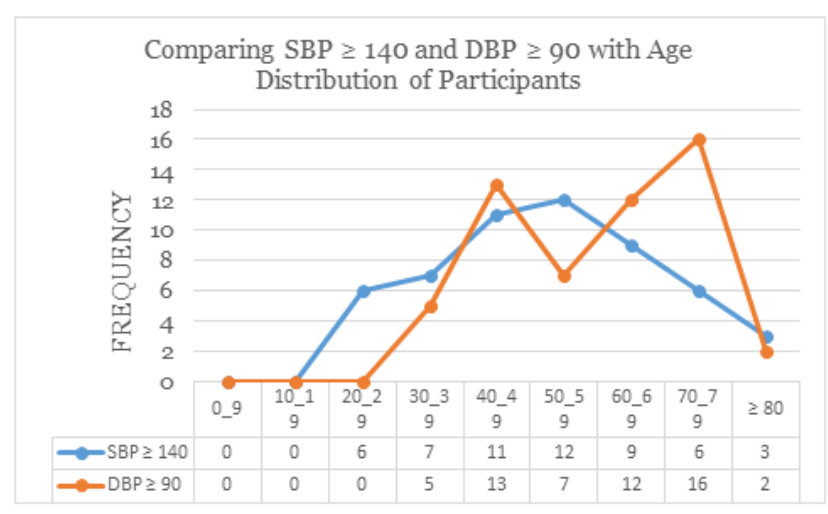

Figure 1. Hypertension vs Gender 


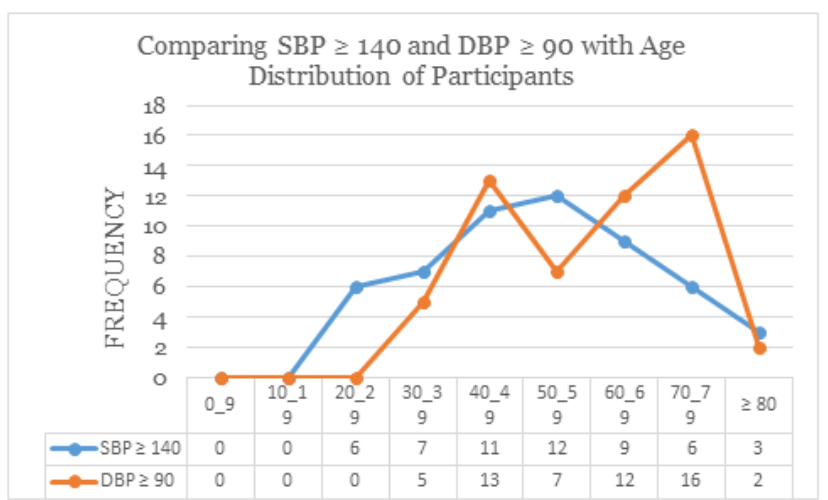

Figure 2. Comparing Hypertension with age distribution of participants

\section{REFERENCES}

[1] Chobanian AV, Bakris GL, Black HR, Cushman WC, Green LA, Izzo JL Jr et al. Seventh Report of the Joint National Committee on Prevention, Detection, Evaluation and Treatment of High Blood pressure. Hypertension;2003:42-6.

[2] S YSR, S O, S A. Global burden of cardiovascular diseases: part 1; general considerations, the epidemiologic transition, risk factors, and impact of urbanization. Circulation;2001:104-2746.

[3] Modesti PA, Agostoni P, Agyemang C, Basu S, Benetos A, Cappuccio FP, et al. Cardiovascular risk assessment in low-resource settings: a consensus document of the European Society of Hypertension working group on Hypertension and Cardiovascular Risk in low Resource settings. J Hypertens;2014:32-5.

[4] Forecasting the future of CVD in the United States: A policy statement from the. American Heart Association Circulation;2011:123-933.

[5] Martinez-Gonzala MA, Bes-Rastrollo M. Dietary patterns, Mediterranean diet and Cardiovascular Disease. Curr Opin lipidol;.

[6] Steven Van de Vijver, Hilda Akinyi, Samuel Oti, Ademola Oajide, Charles Agyemang, Isabella Aboderin, Catherine Kyobutungi. Status report on hypertension in AfricaConsultive review for the 6th session. of the African Union Conference of Ministers of Health on NCD's;

[7] Yilgwan CS, Hyacinth HI, Ige OO, Abok II, Yilgwan G, John C, Isichei CO, Okolo SN, Bode-Thomas F. Cardiovascular disease risk profile in Nigerian school children. Sahei Med J;20:143-8.

[8] Vander. Cardiovascular disease in Sub-Saharan Africa: A disaster waiting to happen. Neth J Med;2003:61-2.

[9] Reddy K, Yusuf S. Emergency epidemic of cardiovascular disease in developing Countries. Circulation; 1998.

[10] Akpan UEE, Udo AIA, and. Bassey Edet Bassey. Prevalence of Hypertension in Akwa Ibom State, South-South Nigeria: Rural versus Urban Communities study, "International. Effiong Ekong. 2015;2015. Available from: https: //doi.org/10.1155/2015/975.

[11] Adelapo K, Falase A.O, A prevalence of cardiometabolic risk factors among a rural Yoruba South-Western Nigerian population: A population-based survey,". Cardiovascular J of Afr;2010(21):26-31.

[12] Andy JJ, Peter EJ, Ekrikpo UT. Prevalence and correlates of hypertension among the Ibibio/Annangs, Efiks and Obolos. A cross sectional Community Survey in rural South-
South Nigeria. Ethn Dis;2012:22-353.

[13] Ahaneku G I, Osuji CU, Anisioba BC, Ikeh VO, Oguejiofor OC, Ahaneku JE. Evaluation of blood pressure and indices of obesity in a typical rural community in Eastern Nigeria. Ann Afr Med; 2011.

[14] Onen CL. Epidemology of Ischaemic heart disease in SubSaharan African. Cardiovascular J Afr;2013:24-2.

[15] Jane Goudge, Lucy Gilson, Steven Russell, Tebogo Gumede, Anne Mills. Affordability, availability and acceptability barriers to healthcare for the chronically ill: Longitudinal case studies from South Africa. BMC Health serv Research;2009(9). 1186/1472 - 6963-9-75.

[16] P ASW. Delivery of diabetes care in rural Ethiopia: an experience from Condar. Ethiop Med J;2003:41-9.

[17] A Sub- Saharan African perspective of diabetes. Diabetologia;1(8-16):00125-008.

[18] Rotimi CN, Cooper RS, Ataman SL, Osotimehin B, Kadiri S, Muna W, Kingue S, Fraser H, MC Gee D. Distribution of anthropometric variable and the prevalence of obesity in populations of West African Origin: The international Collaborative study on Hypertension in blacks (ICSH IB) Obesity research; 1995.

[19] Burl VL, Cutler JA, Higgins M, Horan MJ, Labar the D, Whelton $\mathrm{P}$ et al. Trends in the prevalence, awareness, treatment, and control of hypertension in the adult US population data from the health examination surveys, 1960 to 1991. Hypertension; 1995.

[20] SV DAM. Rapid stick methods for determining of blood glucose concentrations. BMJ;1:293.

[21] A global brief on Hypertension. Silent Killer, global public. World Health Organization. 2013;2013.

[22] Organization Obesity: Preventing and managing the global epidemic. World Health. 2000;

[23] J LDA. Hypertension in Sub-Saharan Africa: A systematic review. Hypertension; 2007.

[24] Ohene-Buabeng K, Matowe L, Plange- Rhule J. Unaffordable drug prices. The major cause of non-compliance with hypertension medication in Ghana. J pharm Sci;2004:7-350.

[25] Roland Wonder Atinyi, Wisdom Takramah, Wisdom Kudzo Axame, Richard Owusu, Phyllis Atta Parbey, Mohammed Takase, Elvis Tarkang, Markin Adjuik, Margaret Kweku. Prevalence of hypertension and pre-hypertension and awareness among Adults in Keta Municipality of. Ghana J Public Health Pharmacol Toxicol;2017(2):1-10.

[26] Mbanya, Prof Ayesha A. Prof Jean Claude N. 2010;375:9733-2254.

[27] Pastakia CRSD. Pekny and Lydia Fischer Diabetes in subSaharan Africa - from policy to practice in Progress: targeting the existing gaps for future care for diabetes 2017. Diabetes Metab. Syndromes;10:247-263.

[28] Ohwovoriole AE, Kuti JA, Kabiawa SI. Casual Blood glucose levels and prevalence of undiscovered Diabetes Mellitus in Lagos Metropolis Nigerians. Diabes Res Clin Pract; 1988.

[29] and classification of Diabetes Mellitus. Diabetes Care 2014; 37 (Suppl) 581-590. American Diabetes Association Diagnosis;10:2337-14.

[30] John COI, Okolo SN. Christopher Sabo Yigwan; Hyacinth Iduh Hyacinth, Olukemi Omowumi Ige, Ibrahim Ishaya Abok, Gavou Yilgwan. vol. 20. Collins;. 
RISK FACTORS FOR CARDIOVASCULAR EVENTS IN RURAL NIGERIA: A CROSS SECTIONAL SURVEY AND A REVIEW OF THE CURRENT

LITERATURE 375

\section{AUTHOR BIOGRAPHY}

Anthonia A. Ikpeme Department of Radiology, University of Calabar, Nigeria

Nchiewe E. Ani Department of Radiology, University of Calabar, Nigeria

Edoise M. Isiwele Department of Radiology, University of Calabar, Nigeria

Andrew E. Ekpenyong Department of Physics, University of Creighton, Nebraska. USA

Emmanuel E. Ekanem Department of Paediatrics, University of Calabar, Nigeria 